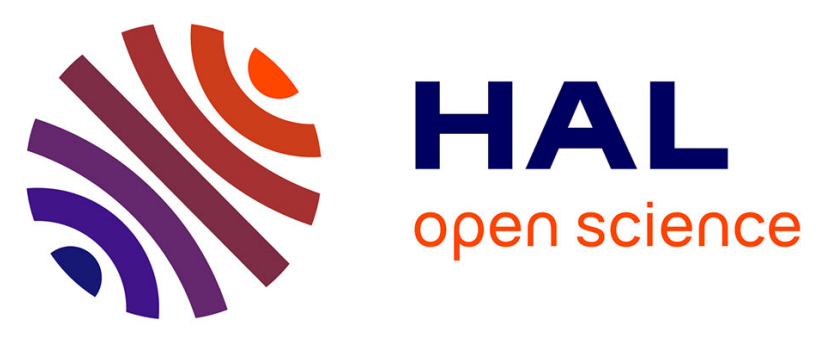

\title{
Surface response meta-models for the assessment of embankment frictional angle stochastic properties from monitoring data: application to harbour structures
}

Franck Schoefs, K. T. Le, Francesca Lanata

\section{- To cite this version:}

Franck Schoefs, K. T. Le, Francesca Lanata. Surface response meta-models for the assessment of embankment frictional angle stochastic properties from monitoring data: application to harbour structures. Computers and Geotechnics, 2013, 53 (2013), pp.122-132. 10.1016/j.compgeo.2013.05.005 . hal-01007257

\section{HAL Id: hal-01007257 \\ https://hal.science/hal-01007257}

Submitted on 16 Jun 2014

HAL is a multi-disciplinary open access archive for the deposit and dissemination of scientific research documents, whether they are published or not. The documents may come from teaching and research institutions in France or abroad, or from public or private research centers.
L'archive ouverte pluridisciplinaire HAL, est destinée au dépôt et à la diffusion de documents scientifiques de niveau recherche, publiés ou non, émanant des établissements d'enseignement et de recherche français ou étrangers, des laboratoires publics ou privés. 


\title{
Surface response meta-models for the assessment of embankment frictional angle stochastic properties from monitoring data: An application to harbour structures
}

\author{
F. Schoefs ${ }^{\mathrm{a}, *}$, K.T. Le ${ }^{\mathrm{a}, \mathrm{b}}, \mathrm{F}$. Lanata ${ }^{\mathrm{c}}$

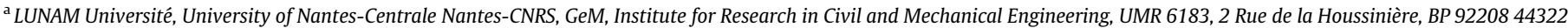 \\ Nantes Cedex 3, France \\ ${ }^{\mathrm{b}}$ The University of Danang-University of Science and Technology (UD-UST), 54 Nguyen Luong Bang Street, Lien Chieu District, Danang City, Viet Nam \\ ${ }^{\mathrm{c}}$ LUNAM Université, Groupe Ecole Supérieure du Bois, Rue Christian Pauc, BP 1060544036 Nantes Cedex 3, France
}

For several decades, many structures have been monitored during maintenance or during their service lives to analyse long-term behaviour. A large number of sensors, properly distributed in the structure, are necessary, especially if the structure is complex and includes significant spatial variability. When probabilistic modelling is applied, because of intrinsic uncertainties in the model as well as uncertain physical parameters, monitoring measurements can be used to identify the parameters of the structural model. This paper presents a monitoring example of a pile-supported wharf in which tie rods are instrumented and the geotechnical characteristics of the soil embankment are identified. The modelling is performed using a meta-model fitted with a numerical database obtained from direct simulations with a finite element model implemented with Plaxis. A full quadratic response surface model (RSM) is the most efficient approximation to fit the original finite element model. The identified soil parameters enable the model to describe the variability of the measured loading in the tie rods.

\author{
Keywords: \\ Monitoring \\ Wharves \\ Soil variability \\ Response surface methodology \\ Inverse analysis
}

\section{Introduction}

In the context of maintenance and redesign of existing structures, the improvement of in-service behaviours requires the application of a wide range of technical and methodological tools to provide decision support for rational tools. Such tool includes data collection, which provides feedback, as well as the modelling of progressive phenomena, such as fatigue and corrosion, which is predictive. Systematic predictive maintenance programs are not easy to implement in systems with large infrastructures because of the heterogeneity of building ages and building styles. This is especially true for structures in coastal areas [1,2]. A survey of the structures (displacement data) provides some additional information, but it is still challenging to update the model if many different factors are involved. Thus, intrusive structural monitoring of complex structures is the only way to accomplish the following: (a) measure the actual in-service behaviour influenced by building conditions and settling, the factors expected to separate the present behaviour from the theoretical one [3-5]; and (b) understand complex interaction mechanisms, such as soil-structure interaction [6,7].

Because of the randomness of each building materials (concrete, embankment) and natural properties of materials (soil), probabilis-

\footnotetext{
* Corresponding author. Tel.: +33 (0) 2511255 22; fax: +33 (0) 251125557.

E-mail address: franck.schoefs@univ-nantes.fr (F. Schoefs).
}

tic methods are becoming more and more popular. These methods constitute a theoretical framework in which one can address uncertainties involved in the structural assessment of buildings with respect to sensitivity analyses or reliability assessments.

In this study, the physical and mechanical properties of a powdery embankment for soil pressure quantification are characterised. The randomness of the soil properties from the monitoring of tie rods in a wharf is also characterised. First, a complete model of the wharf is suggested, and then a meta-model is proposed as a surrogate to this complex and time-consuming model. Several polynomial response surfaces are introduced as solutions, and samples are constructed to fit these meta-models to a data base probabilistically. Finally, the soil properties are identified and the analysis focusses on the frictional angle.

\section{Description of the structure, the instrumentation and the available data}

\subsection{Description of the structure}

The structure is station 4 , which is an extension of the timber terminal of Cheviré, and is named Cheviré-4 wharf. Cheviré-4 wharf is located downstream of the Cheviré bridge near the city of Nantes (in western France), in a river environment, on the left bank of the Loire River. It is $180 \mathrm{~m}$ long and $34.5 \mathrm{~m}$ wide. Collabo- 
ration with the Port Authority of Nantes Saint-Nazaire (PANSN) permitted a survey of the structure. A sketch of a typical cross section, showing the primary components, is presented in Fig. 1. Each component plays a specific role in the function of the pile-supported wharf.

\subsection{Structural instrumentation}

The instrumentation strategy follows the global behaviour of the wharf for at least 5 years post-construction. The goal of the study is to improve prediction models. The validated models will allow the maintenance policy to be based on an improved understanding of the in-service behaviour of the structure. The large dimensions of these structures, the building hazards and the soil behaviour suggest that the service behaviour would vary from the expected design behaviour, primarily because of conservative choices and the use of highly theoretical hypotheses in the design stage.

The objective is to understand the behaviour of the wharf under horizontal loading, i.e., actions of the embankment, ship berthing and wind action on the cranes; therefore, the tie rods were monitored because they are sensitive elements of the wharf that are not accessible after the building period. The wharf was instrumented on twelve tie rods (regularly distributed along the length of the wharf; see Fig. 2) to follow the normal load on the cross section of the rods. Electric strain gauges were used, mounted in full bridge and bonded to the rods with a high-temperature epoxy resin used for sensor manufacturing; these gauges are linked to a Campbell Scientific CR10X data logger. Wiring the strain gauges in a full bridge ensures temperature self-compensation. The system also ensures corrosion protection of the rods. A tidal gauge (controlled by PANSN) measures the actual tide level every $5 \mathrm{~min}$; the tidal gauge is located $1 \mathrm{~km}$ downstream from the Chevire Bridge. This measurement enables adjustment of the data for the over-crests from the air pressure, the rate of the river flow and the wind.

\subsection{Available data}

The loads in the tie rods were measured for 2 years (January 2004-October 2005) and have been analysed by Yáñez-Godoy et al. [8]. Two types of variations characterise the loads in the tie rods:

- Temporal: medium-term variations, where the load levels change within a month (approximately one period of the moon's rotation), and short-term variations, where the load amplitudes change with the tides (a period of approximately $12 \mathrm{~h}$ ); and

- Spatial: variations of the loads distributed in each tie rod.

An analysis of the spatial load variations is conducted in [8], where significant scatter is shown from one tie rod to another. Yáñez-Godoy et al. [8] showed that this load variation is much more stable from tie rod to tie rod in time within a single tide. The present paper focuses on this behaviour and considers a measurement on each tie rod as an independent measurement of the behaviour of a tie rod placed in a section of the current. After several months, sensors in 4 of the 10 tie rods instrumented in the section (see points on Fig. 2) were disabled; thus, this study uses the data collected from the 6 remaining sensors, i.e., T4, T11, T17, T21, T31 and T34, underlined in Fig. 2.

\subsection{Primary assumptions for the probabilistic modelling using the spatial profile and time series}

For a decade, investigations of structural behaviour using nondestructive testing or monitoring have stressed the need for improved methods of data processing and structural computation. The time series for this type of application can be roughly classified into three categories as follows:

- Time series describing the evolution of the ageing phenomena, such as chloride ingress in concrete and crack propagation;

- Time series measuring the strain produced by non-periodic loadings, such as wind loading and truck loading; and

- Time series measuring the strain from cyclic loadings, such as temperature, tides or waves.

This study focusses on the data obtained from the last two categories during the training period, i.e., before any ageing occurs. When similar elements, placed at a given location $x_{i}$, are monitored (beams [9] or tie rods [8]) and subjected to the same loading, a statistical study of their loading $L_{T}\left(x_{i}, t, \theta_{j}\right)$ can be performed, where $t$ denotes the time and $\theta_{j}$ is the event that represents the primary hazard during construction and composition of the material around the monitored elements. In this context, $\theta_{j}$ is a term that describes the hazard $\theta$ when $\theta \in \Omega$ (the probabilistic space that gathers all the hazard inputs that generate events), thus including the random variables (material properties, tide level, etc.). Practically, the measurement in a tie rod (i.e., at position $x_{i}$ ) at a given time $t$ is unique and is represented by $L_{T}\left(x_{i}, t\right)$. After understanding the physical mechanisms involved in this study, several assumptions provide the foundation for the statistical analysis:

- First, when structural components are buried in the ground (sheet piles, piles, rods, etc.) and are submitted to daily cyclic variations of the water level (tides), the water level changes modify the granular soil structure with time and with respect to the composition of the surrounding material. Thus, if two measurements of the loading at times $t_{1}$ and $t_{2}$ are performed and the period between $t_{2}$ and $t_{1}$ is long enough (several weeks), it can be assumed that they are independent measurements of the loading in the tie rod. That will be the case in the following

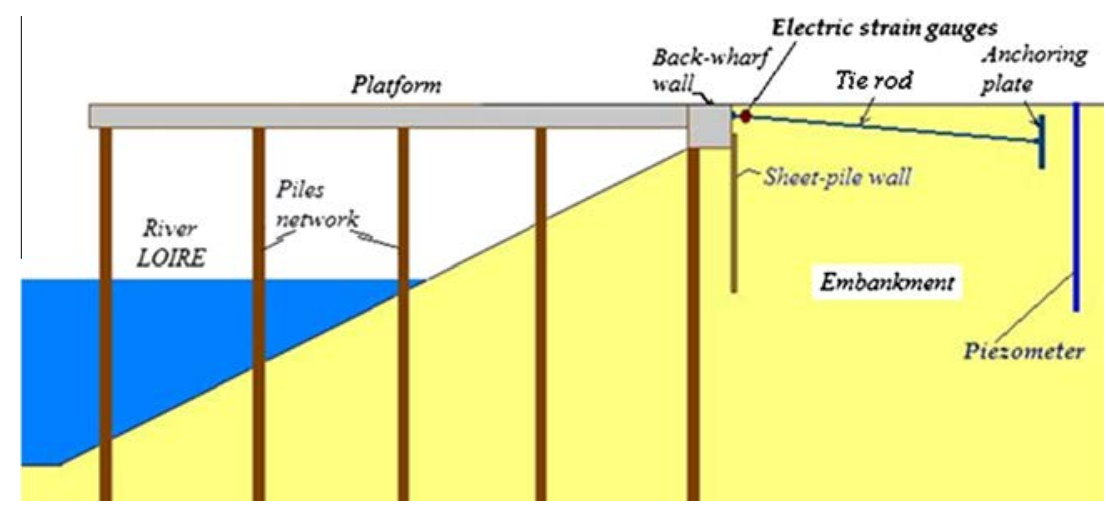

Fig. 1. Cross section of the wharf. 


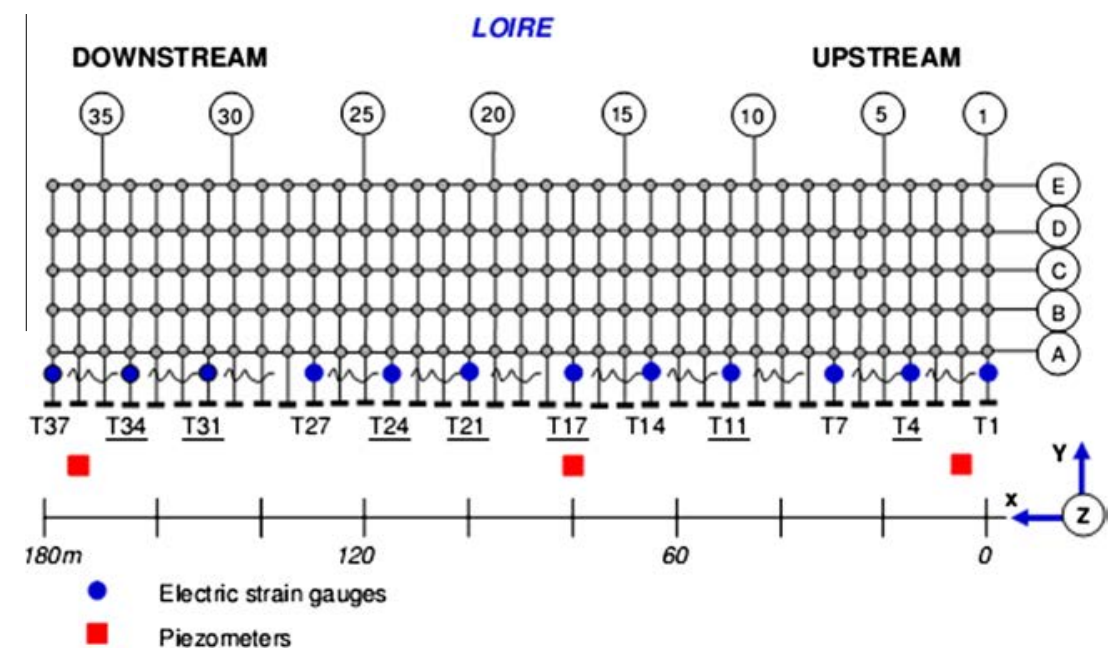

Fig. 2. View of the instrumentation plan.

between two tides with the same tidal coefficient (see Section 5.1). It thus becomes a loading on the same component in different material conditions. With this assumption, and for simplification, $L_{T}\left(x_{i}, t_{k}\right)$ is replaced by $L_{T}\left(x_{i}, \theta_{k}\right)$.

- Second, this study relies on the analysis of the loading during tidal variations. In that case, the spatial correlation between the loads at several positions $L_{T}\left(x_{i}, \theta\right)$ and $L_{T}\left(x_{j}, \theta\right)$ cannot be proven [8]. Thus, $L_{T}\left(x_{i}, \theta_{k}\right)$ are considered spatially independent. $L_{T}(-$ $\left.x_{i}, \theta_{k}\right)$ can therefore be replaced by $L_{T}\left(\theta_{k}\right)$. Fig. 3 shows the evolution of the sensitivity of the loading. In the figure, $\Delta H$ is the water level change in Loire River during a falling tide for a given tie rod (T1) and for three tidal coefficients (CMAR), 42, 69, and 100. In France, the oscillation amplitude of the semidiurnal tide is associated with a dimensionless coefficient, the tidal coefficient (CMAR) (see [8] for more information), with values between 20 and 120 . CMAR is computed as follows:

$\operatorname{CMAR}=\frac{\Delta H(t)}{\Delta H_{e}}$

where $\Delta H(t)$ and $\Delta H_{e}$ are the difference between high and low tide levels at time $t$ and during mean high water springs and mean low water springs near the equinox date (i.e., 21 March or 21 September). CMAR assists in finding similar tidal conditions; however, the loading is affected by the water level of the Loire River. That is most likely why there is a small change in sensitivity (less than $2 \mathrm{kN} / \mathrm{m}$ ) with time for CMAR $=69$ and CMAR $=100$ (Fig. 3 ); the scatter is much larger for CMAR $=42$. Because a lower CMAR implies low load levels in the tie rods, other phenomena than tides are contributing to these changes. The goal of this study is to provide a probabilistic model of the soil properties to use for reliability analyses of wharves during storms [10]. These extreme events occur primarily in winter when CMAR is higher. Consequently, the horizontal wharf behaviour will be analysed only for CMAR $>69$.

\section{Numerical modelling and meta-model assessment}

\subsection{Numerical strategy}

Numerical models are integrated in an optimisation procedure to identify the soil properties. Computation time should be as short as possible because of the large number of calls to the model necessary for the optimisation problem. Thus, starting from a completely two-dimensional finite element model (FEM) developed in the Plaxis environment [11], the best meta-model $M\left(X\left(\theta_{j}\right)\right)$, with

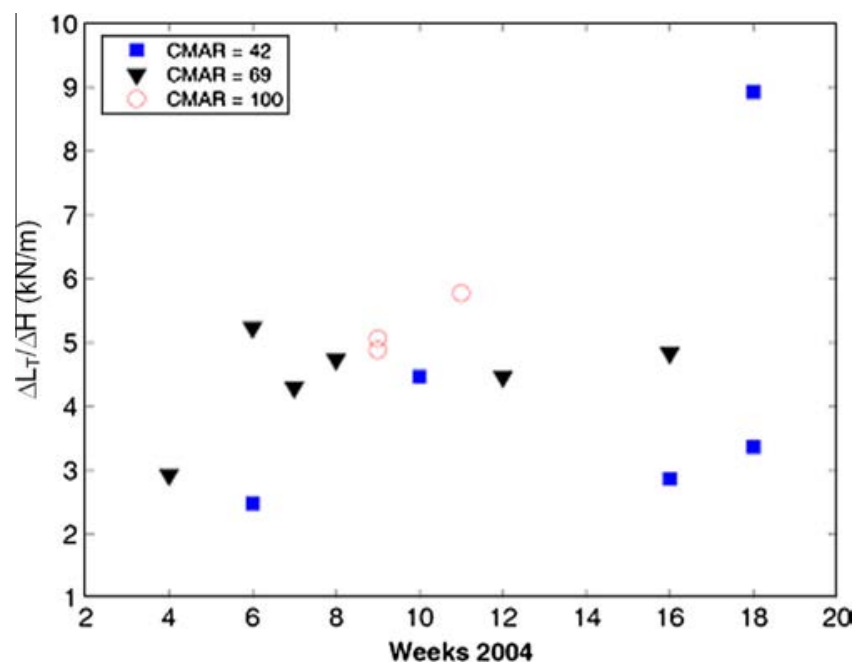

Fig. 3. Variation with time of sensitivity of the measured normal load $\Delta L_{T}$ in tie rod T1 for a falling tide (CMAR $=42,69$ and 100).

$X\left(\theta_{j}\right)$ random input variables, that represents the desired behaviour is chosen. The choice of Plaxis is governed by the ease of implementing the phases of real construction and refurbishment through the interface and also by the wide set of soil properties and behaviour available. Plaxis is also a well-known tool that has provided realistic behaviours of geotechnical structures in the past. Several meta-models have been developed for deterministic or probabilistic analyses of wharves during the past two decades, e.g., neuronal and Bayesian networks $[12,13]$, spectral stochastic finite element models based on regression or projection methods $[14,15]$, and polynomial or other response surfaces.

Quadratic polynomial response surfaces are chosen for this model because of their asymptotic properties [13,16-18].

\subsection{Finite element model}

The structure is modelled using a Plaxis finite element model by including all the construction phases. Fig. 4 shows the geometry and the modelled soil levels, as listed in Table 1. The upper layer, Layer 1, in which the tie rods are placed, has the most important effect on the behaviour during a tide and therefore only its behaviour is modelled using random variables. A 2-D model is used to represent a standard cross section, not affected by the edges and 
consistent with the assumptions in Section 2.4. A barbican (drainage channel) is installed $3 \mathrm{~m}$ under the embankment surface to reduce the water pressure on the wharf when the tide is falling. The effect of the flow in the soil under the screen is neglected because of the presence of the sheet pile.

The main characteristics of the mechanical model are shown in Table 2 (see [15] for further details). The back-wharf wall has an Lshape and is composed of two plates (Fig. 4).

Several models have been tested to determine the limiting conditions for the anchoring plate at one end of the tie rod; plate and geogrid models are the most-used. The best model to follow the tide loading with time is found to be the geogrid model. For the same reason, the connection between the back-wharf wall and the sheet pile is modelled through a hinge. Schoefs et al. [15] have shown that the concrete platform and the piles can be modelled by an embedded horizontal beam with deterministic behaviour (see Fig. 4); the rigidity of the platform in the horizontal plane reduces the variance of each pile connected to it and is much larger than the tie rod's axial rigidity. In this case, the tie rod is passive, with an unknown preload applied manually, as is usual for this type of structure.

During a tide, the water level varies in both the embankment and the river. Six phases have been used to describe each tidal cycle, as shown in Table 3 and explained in Section 4.1. The values are for a tidal coefficient CMAR = 69; this tidal coefficient has been selected because it is both high and common (i.e., there are sufficient number of occurrences during the period of monitoring). Fig. 5 gives a schematic example of the water levels in the embankment and in the river for phases 1 and 6 .

\subsection{Meta model: quadratic response surfaces}

In current research, many types of response surface functions have been tested for different applications. There are two general types of functions in current use $[13,16]$ : the physical response function and the analytical response function. This analysis focuses on an analytical response function defined by a polynomial of order less than 3, with or without interaction terms, known as a quadratic response surface (QRS). QRS has been developed in several fields [19-22]. This form has specific properties, e.g., asymptotic behaviour for the transfer of distribution tails, which fit the physical problem in this study. This property is essential when only a few experiments are available, to ensure a realistic transfer of distribution tails $[18,23]$.

The general form of the full QRS is as follows:

$$
L_{T, S R}=b_{0}+\sum b_{i} X_{i}+\sum_{i \neq j} b_{i j} X_{i} X_{j}+\sum_{i} b_{i i} X_{i}^{2}
$$

where $L_{T, S R}$ is the load in the tie rod, $X_{i}$ is the $i$ th random variable and $b_{k}$ coefficients are determined by regression from a numerical test plan based both on the probabilistic distribution of the variables (distribution of numerical values) and on their potential influence on the response (number of numerical values, i.e., size of the sample, for each variable).

Setting each of the coefficients equal to zero, various mathematical models are formed and compared to experimental data, and the coefficients are determined using the response surface function. These models are the following:

- Full quadratic.

- Linear if $b_{i j, i \neq j}=0$ and $b_{i i}=0$.

- Pure quadratic if $b_{i}=0$ and $b_{i j, i \neq j}=0$.

- Linear with interaction if $b_{i i}=0$.

As the model becomes more complex, more data are needed to identify the coefficients.

\section{Random variables and probabilistic modelling}

\subsection{Numerical experimental design}

To identify the values of the coefficients $b_{k}$ in Eq. (2), a QRS has been fitted to a numerical database with a probabilistic meaning, i.e., samples are generated from a probability density function for each variable. The basic random variables considered are the following: $\gamma_{\text {sat }}$ and $\gamma_{\text {unsat }}$, the saturated and unsaturated density of the soil (levels 1 and 2), respectively; $E$ and $v$, Young's and Poisson's moduli, respectively; and $\varphi$, the internal frictional angle. The cohesion, $c$, is ignored. The structure is analysed during the first 2 years when there is no exploitation by ships.

The range of variation for each variable is selected from the literature or preliminary knowledge. Available published data for sand (soil level 2) and embankment (soil level 1) are shown in Table 4.

Based on the data in Table 4, the basic random variables, their distribution, the parameters (or the range if bounded) of the distributions and the values selected for the experimental design (in bold) are shown in Table 5. A uniform distribution was selected for the soil parameters because of a lack of previous knowledge; with this type of distribution, considerable weight is given to values in the distribution tails. The following deterministic functional relationship is used to relate the unsaturated density, $\gamma_{\text {unsat }}$, to the saturated density, $\gamma_{\text {sat }}$, of the embankment to reduce the number of independent variables: $\gamma_{\text {sat }}=\gamma_{\text {unsat }}+2$.

With respect to the tide-river level and the corresponding water level in the embankment (soil level 1), a tide with a high and fre-

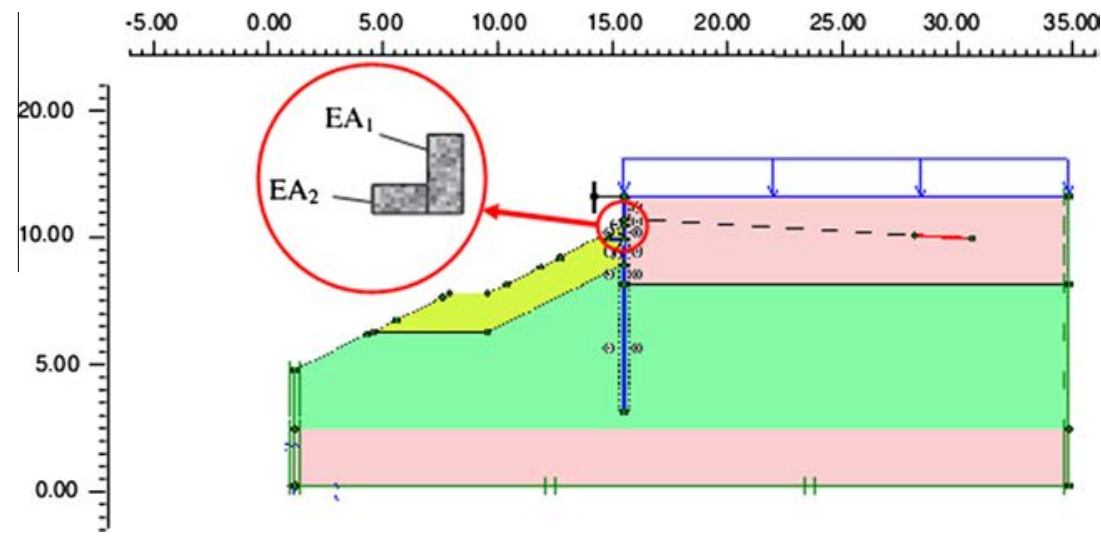

Fig. 4. Geometry modelled in the Plaxis environment by the FE model. 
Table 1

Main properties of the soil levels.

\begin{tabular}{|c|c|c|c|c|}
\hline Soil level & Type of soil & Material model & Type of material behaviour & Thickness (m) \\
\hline Level 1 & Embankment & Mohr-Coulomb & Drained & 4.0 \\
\hline Level 2 & Recent alluvium, fine to coarse grey sand, little clay & Mohr-Coulomb & Drained & 8.0 \\
\hline Level 3 & Surface rock talus & Mohr-Coulomb & Drained & 2.0 \\
\hline Level 4 & Recent alluvium, coarse grey sand, little clay, compact under $6.6 \mathrm{~m}$ & Mohr-Coulomb & Drained & $>20$ \\
\hline
\end{tabular}

Table 2

Main structural characteristics.

\begin{tabular}{|c|c|c|c|c|c|c|}
\hline Structural component & Mechanical behaviour & $E A(\mathrm{kN} / \mathrm{m})$ & $E I\left(\mathrm{kN} \mathrm{m}^{2} / \mathrm{m}\right)$ & $\gamma(\mathrm{kN} / \mathrm{m} / \mathrm{m})^{\mathrm{a}}$ & $v$ & $E\left(\mathrm{kN} / \mathrm{m}^{2}\right)$ \\
\hline Spring (platform + piles) & Linear elastic & $20.91 \times 10^{3}$ & & & & \\
\hline Plate (back-wharf wall) & Linear elastic & $\begin{array}{l}E A_{1}=3.08 \times 10^{4} \\
E A_{2}=1.4 \times 10^{4}\end{array}$ & $\begin{array}{l}E I_{1}=410.7 \\
E I_{2}=746.7\end{array}$ & $\begin{array}{l}22.8 \\
20.8\end{array}$ & 0.1 & 35,000 \\
\hline Tie rod & Linear elastic & 971,437 & & & & \\
\hline Geogrid (c-anchoring plate) & Linear elastic & $10^{5}$ & & & & \\
\hline Sheet piles & Linear elastic & $3.32 \times 10^{6}$ & $6.45 \times 10^{4}$ & 1.245 & 0.1 & $210 \times 10^{6}$ \\
\hline
\end{tabular}

${ }^{\text {a }} \gamma$ Is the weight per linear meter of wharf per meter of depth.

Table 3

Water level at selected phases during a tide for $\mathrm{CMAR}=69$.

\begin{tabular}{lll}
\hline Phase & River level $(\mathrm{m})$ & Water level in embankment $(\mathrm{m})$ \\
\hline Phase 1 & 6.21 & 5.19 \\
Phase 2 & 5.75 & 5.39 \\
Phase 3 & 4.84 & 5.19 \\
Phase 4 & 4.17 & 4.96 \\
Phase 5 & 2.98 & 4.54 \\
Phase 6 & 2.19 & 4.13 \\
\hline
\end{tabular}

quent CMAR of 70 is analysed. In the 2-year database, a CMAR of 69 was observed on March 2nd, 2005 with a high level, $H_{\max }=6.21 \mathrm{~m}$, and a low level, $H_{\min }=2.19 \mathrm{~m}$, measured from sea level along the French coast. Fig. 6 shows the distribution of the tide-river levels measured during the 2 years. The data show that the values of $H_{\max }$ and $H_{\min }$ corresponding to the selected tide are representative of the mean values of each distribution, so that the chosen tide can be considered as a representative tide. Further, the tide-river level has been discretised in six phases between the values $H_{\max }$ and $H_{\min }$ to model a good representation of potential situations during the tide (Table 3). They can also be tested as other extreme tide levels. For each water level, the water level in the embankment has been measured and is reported in Table 3. Water levels for phases 1 and 6 are shown in Fig. 5. From this experimental design, using the basic random variables, which are assumed to be independent, 450 computations are performed with the Plaxis finite element model.

The sand characteristics (soil level 2) are considered deterministic because they have a weak influence on the horizontal behaviour. According to Table 4, the values assumed for the computation
Table 4

Review of intervals for sand and embankment characteristics.

\begin{tabular}{llll}
\hline Type of soil & Variables & Value & Refs. \\
\hline Sand & Density $\left(\mathrm{kN} / \mathrm{m}^{3}\right)$ & & \\
& Saturated, $\gamma_{\text {sat }}$ & {$[17: 1]$} & {$[24-26]$} \\
& Non saturated, $\gamma_{\text {unsat }}$ & {$[16: 20]$} & {$[24-27]$} \\
& Young's modulus, $E(\mathrm{Mpa})$ & {$[3: 120]$} & {$[24-27]$} \\
& Frictional internal angle, $\varphi\left(^{\circ}\right)$ & {$[25: 40]$} & {$[24-29]$} \\
& Poisson's modulus, $v(-)$ & {$[0.3: 0.45]$} & {$[24-26,29]$} \\
& Cohesion, $c(\mathrm{kPa})$ & {$[0: 20]$} & {$[25-28]$} \\
Embankment & & \\
& Density $\left(\mathrm{kN} / \mathrm{m}^{3}\right)$ & {$[17.5: 22]$} & {$[25,30]$} \\
& $\gamma_{\text {sat }}$ & {$[16: 20]$} & {$[17,25,31-34]$} \\
& $\gamma_{\text {unsat }}$ & {$[2: 100]$} & {$[24,25,32,33]$} \\
& $E(\mathrm{Mpa})$ & {$[25: 38]$} & {$[17,25,31,32,34]$} \\
& $\varphi\left({ }^{\circ}\right)$ & {$[0.25: 0.3]$} & {$[17,25,31,32]$} \\
& $v(-)$ & {$[0: 20]$} & {$[17,25,31-34]$} \\
& $c(\mathrm{kPa})$ &
\end{tabular}

are $\gamma_{\text {unsat }}=19 \mathrm{kN} / \mathrm{m}^{3}, E=30 \mathrm{MPa}, \varphi=30^{\circ}, v=0.001$ and dilatancy angle, $\psi=0$.

\subsection{Uncertainty and sensitivity analysis for the basic random variable selection}

With the six random variables presented in Table 5,28 coefficients, $b_{k}$, must be calibrated to fit a full quadratic response surface. This calibration requires a database that contains more than 450 simulations. Consequently, this initial numerical database is used to highlight the most influential random variables and to reduce the total number of BRVs required. All the results are available in
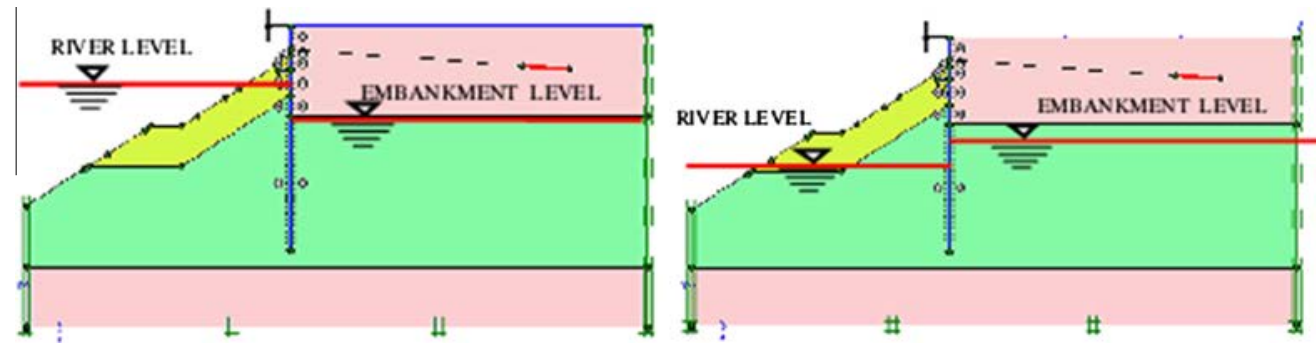

Fig. 5. Water levels in the embankment and in the river for phases 1 (left) and 6 (right). 
Table 5

Pre-selection of variables and relative distributions.

\begin{tabular}{|c|c|c|c|}
\hline Variables & Distribution & Size of the support/parameters & Selected values for simulation \\
\hline \multicolumn{4}{|l|}{ Density $\left(k N / m^{3}\right)$} \\
\hline$\gamma_{\text {sat }}$ & & Relationship with $\gamma_{\text {unsat }}$ & \\
\hline$\gamma_{\text {unsat }}$ & Uniform & {$[16: 20]$} & $16,17,18,19,20$ \\
\hline Young's modulus, E (Mpa) & Uniform & {$[30: 50]$} & $30,35,40,45,50$ \\
\hline Frictional internal angle, $\varphi\left(^{\circ}\right)$ & Uniform & {$[25: 35]$} & $25,27,30,32,35 / 25, \mathbf{3 0}, 35$ \\
\hline Poisson's modulus, $v(-)$ & Uniform & {$[0.25: 0.4]$} & $0.25,0.3,0.35,0.4 / \mathbf{0 . 2 7}$ \\
\hline Cohesion, $c(\mathrm{kPa})$ & Deterministic & 0 & \\
\hline High tide level, $H_{\max }(\mathrm{m})$ & Generalised extreme value & $\mu=5.84 ; \sigma=0.69$ & See Fig. 6 \\
\hline Low tide level, $H_{\min }(\mathrm{m})$ & Generalised extreme value & $\mu=1.61 ; \sigma=0.79$ & See Fig. 6 \\
\hline
\end{tabular}

a Values in bold are used for QRS calibration (Section 4.3).

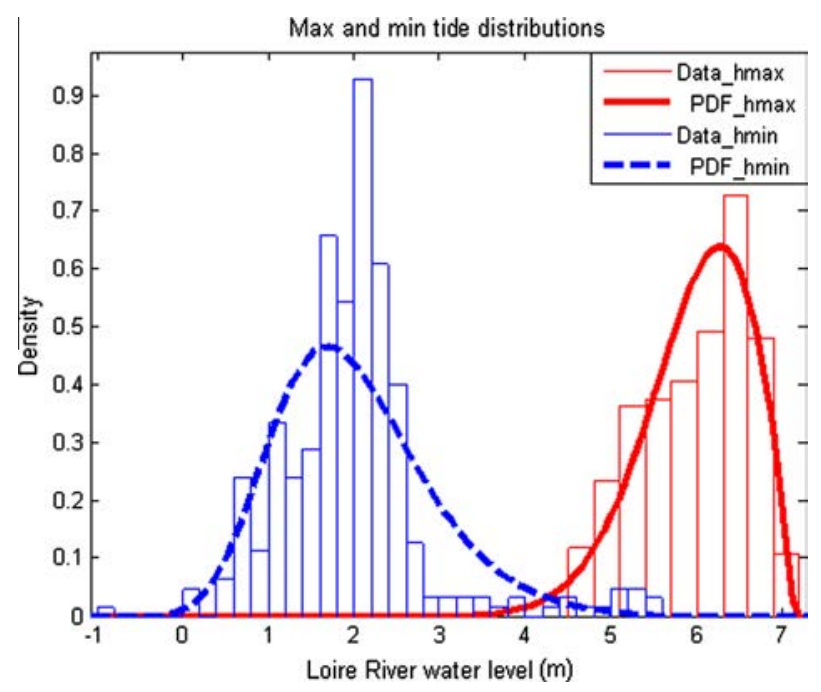

Fig. 6. Distributions of the water level measurements during the 2 years.

[35]. They highlight the following key points: (i) $1 / E$ and $\gamma_{\text {unsat }}$ exhibit similar behaviour in the response (Fig. 7 for the two phases of Fig. 5); thus, it is difficult to identify each variable from a single measurement. This study focusses on the frictional angle and the correlation between $\gamma_{\text {unsat }}$ and $E$, which can then be considered a single random variable $X_{1}=\gamma_{\text {unsat }} / E$; and (ii) $v$ has no influence on the response and can be considered a deterministic parameter. Table 6 shows the results and the conclusions concerning the selected basic random variables (BRV). Four BRVs are selected, which require 15 coefficients, $b_{k}$, to be calibrated for a full quadratic response surface.

\subsection{QRS calibration and selection}

Table 7 shows the 15 coefficients, $b_{k}$, obtained from fitting QRS to the numerical data base using the BRV in Table 6 .

Table 8 shows the values of the residuals computed for the four QRS described in Section 3.3 using different criteria: the mean residual, $\underline{R}$, from Eq. (3); the mean relative deviation of the residual, $\Delta_{r F}$, from Eq. (4); and the likelihood of the parameters in the interval $[-10 \mathrm{kN},+10 \mathrm{kN}]$, corresponding to the uncertainty in the measurement of the loads. Fig. 8 shows the distribution of residuals for each response surface.

$\underline{R}=\frac{1}{N} \sqrt{\sum_{i=1}^{N} R_{i}^{2}}$

$\Delta_{r F}=\frac{1}{N} \sum_{i=1}^{N} \frac{R_{i}}{F_{P l_{i}}}$ where $R_{i}$ and $F_{P l i}$ denote the $i$ th residual and the load value for the $N$ numerical experiments, respectively, and $N=450$.

The full quadratic response surface fit the residuals the best. An example of the simulation results obtained from the Plaxis model (Fpl) and full quadratic and linear response surfaces (Fsr) is shown in Fig. 9. Each plot represents the computed value of loading in one of the tie rods as a function of the RV $X_{1}$. The other BRVs are assumed as follows:

$X_{2}$ (internal frictional angle): three values are analysed $\left(25^{\circ}, 30^{\circ}\right.$ and $35^{\circ}$, according to the variation interval of Table 5); and $X_{3}$ (tide-river level) and $X_{4}$ (water level in the embankment): the six couples of water level corresponding to the six phases of the considered tide (Table 3 ) are analysed.

The plots in Fig. 9 correspond to the minimum water level of the tide from the river side. The blue ${ }^{1}$-coloured points represent the response surface data (the squares, labelled Fsr) and the Plaxis simulation results (the crosses, labelled $\mathrm{Fpl}$ ) for an internal frictional angle of $25^{\circ}$. The red and the magenta-coloured points represent the response surface data (the squares, labelled Fsr) and the Plaxis simulation results (the ics and stars respectively) for internal frictional angles of $30^{\circ}$ and $35^{\circ}$.

The comparison between the full quadratic (left) and the linear (right) response surfaces shows that better agreement with the Plaxis simulations is obtained using the full quadratic model.

\section{Identification of basic random variables}

\subsection{Identification methodology}

Because the water levels in the river and in the embankment are monitored, the BRVs $X_{3}$ and $X_{4}$ are known; thus, the identification procedure focusses on $X_{1}$ and $X_{2}$. A zero-order method (simplex) [36] is used. This method is based on the least squares method: for each tie rod, one instance of the couple of random variables $\left(X_{1}, X_{2}\right)$ is computed from the data of five rising and falling tides (M1-M5) with CMAR $=69$, corresponding to a total of 29 phases. Because of the cyclic evolution of tides with time, several tides of the same CMAR occur during the same year. They are denoted as $M_{j}(j \in[1,5])$ in the following analysis.

The objective function $F_{\text {err }}(\theta)$ of the identification method is written as follows:

$F_{\text {err }}(\theta)=\sum_{i} F_{\text {err }_{i}}^{2}(\theta)=\sum_{i}\left(F_{\text {mes }_{i}}-\left(f_{i}\left(F_{\text {sr }_{i}}, \theta\right)\right)\right)_{i}^{2}=\sum_{i} r_{i}^{2}(\theta)$

where $F_{\text {erri }}$ denotes the deviation between the measured loadings in the $i$ th tie rod $\left(F_{\text {mes }_{i}}\right)$ and the corresponding loading prediction cal-

\footnotetext{
${ }^{1}$ For interpretation of colour in Fig. 9, the reader is referred to the web version of this article.
} 

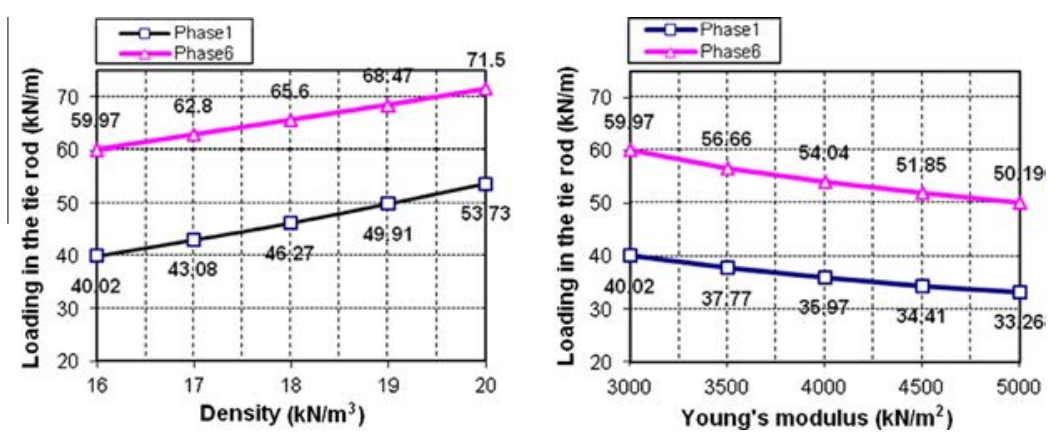

Fig. 7. The influence of the density, $\gamma_{\text {unsat }}$, (left) and Young's modulus, $E$, (right) on the response of the tie rods.

Table 6

Selection of the random input variables for the calibration of the response surface.

\begin{tabular}{|c|c|c|c|}
\hline Initial random variables & Studies & Relationship & Name of selected BRV \\
\hline $\begin{array}{l}\gamma_{\text {unsat }}: \text { Unsaturated density } \\
\text { E: Young's modulus }\end{array}$ & $\begin{array}{l}\text { Variable change } \\
\text { Variable change }\end{array}$ & $X_{1}=\frac{\gamma_{\text {unsat }}}{E}$ & {$\left[X_{1}\right]: \mathrm{RV}$} \\
\hline$\varphi$ : Internal frictional angle & - & $X_{2}=\varphi$ & {$\left[X_{2}\right]:$ BRV } \\
\hline$\gamma_{\text {sat }}:$ Saturate density & $\begin{array}{l}\text { Functional relationship with } \gamma_{\text {unsat }} \\
\text { Sensitivity analysis }\end{array}$ & $\begin{array}{l}\gamma_{\text {sat }}=f\left(\gamma_{\text {unsat }}\right) \text { or } \gamma_{\text {sat }}=\gamma_{\text {unsat }}+\varepsilon \\
\nu=0.27\end{array}$ & $v \mathrm{D}$ \\
\hline Tide-river level & Measured data from CMAR $=69$ & - & {$\left[X_{3}\right]:$ BRV } \\
\hline Water level in the embankment & Measured data from CMAR $=69$ & - & {$\left[X_{4}\right]:$ BRV } \\
\hline
\end{tabular}

Table 7

Coefficients for each QRS after fitting.

\begin{tabular}{|c|c|c|c|c|c|c|c|}
\hline \multicolumn{2}{|c|}{ Full quadratic } & \multicolumn{2}{|l|}{ Linear } & \multicolumn{2}{|c|}{ Pure quadratic } & \multicolumn{2}{|c|}{ Linear with interactions } \\
\hline Coeff. $b$ & Value & Coeff. $b$ & Value & Coeff. $b$ & Value & Coeff. $b$ & Value \\
\hline$b_{0}$ & 1078.497 & $b_{0}$ & 413.9227 & $b_{0}$ & 1119.846 & $b_{0}$ & 105.9889 \\
\hline$b_{1}$ & 415392.2 & $b_{1}$ & 187489.7 & $b_{1}$ & 233947.5 & $b_{1}$ & 368934.4 \\
\hline$b_{2}$ & -52.9327 & $b_{2}$ & -12.5576 & $b_{2}$ & -61.1056 & $b_{2}$ & -4.38475 \\
\hline$b_{3}$ & -57.1674 & $b_{3}$ & -41.1804 & $b_{3}$ & -21.1729 & $b_{3}$ & -92.6383 \\
\hline$b_{4}$ & 28.75112 & $b_{4}$ & 54.71852 & $b_{4}$ & 51.93122 & $b_{4}$ & 167.327 \\
\hline$b_{12}$ & -5041.22 & & & & & $b_{12}$ & -5041.22 \\
\hline$b_{13}$ & -9538.02 & & & & & $b_{13}$ & -9538.02 \\
\hline$b_{14}$ & 2315.487 & & & & & $b_{14}$ & 2315.487 \\
\hline$b_{23}$ & 2.594443 & & & & & $b_{23}$ & 2.594443 \\
\hline$b_{24}$ & -3.49643 & & & & & $b_{24}$ & -3.49643 \\
\hline$b_{34}$ & -11.9983 & & & & & $b_{34}$ & -4.10185 \\
\hline$b_{11}$ & $-4.8 \mathrm{E}+07$ & & & $b_{11}$ & $-4.8 \mathrm{E}+07$ & & \\
\hline$b_{22}$ & 0.809133 & & & $b_{22}$ & 0.809133 & & \\
\hline$b_{33}$ & 0.476507 & & & $b_{33}$ & -1.76462 & & \\
\hline$b_{44}$ & 17.31634 & & & $b_{44}$ & -1.58927 & & \\
\hline
\end{tabular}

Table 8

Residual criteria for each type of QRS.

\begin{tabular}{|c|c|c|c|c|}
\hline Criteria & Full quadratic & Linear & Pure quadratic & Linear with interaction \\
\hline Residuals Eq. (3) & 0.343 & 0.732 & 0.574 & 0.566 \\
\hline Residuals Eq. (4) & 0.031 & 0.067 & 0.051 & 0.049 \\
\hline Likelihood & 0.83 & 0.48 & 0.58 & 0.59 \\
\hline
\end{tabular}

culated by the RS numerical model, $f\left(F_{s r_{i}}, \theta\right)$, and $\theta$ is the set of unknown variables to be identified and $i$ is the phase number (e.g., $i \in[1,6]$ for the tide in Table 3, Fig. 5).

The prediction $f\left(F_{s r_{i}}, \theta\right)$ can be written as follows:

$f_{i}\left(F_{s r_{i}}, \theta\right)=F_{0}+F_{s r_{i}}$

where $F_{0}$ is the pre-loading during the installation of the tie rod and $F_{s r_{i}}$ is the loading in the tie rod calculated by RS. The value of $F_{0}$ is different for each tie rod and is calculated in the identification process of the variables. By definition, it is assumed to be constant with time and deterministic for a given tie rod. As different values of $F_{0}$ can be obtained for tides $M_{j}$, a two-stage procedure is selected. Stage (1) calculates the values of $F_{j 0}, X_{j 1}^{(1)}$ and $X_{j 2}^{(1)}$ using Eq. (5) for each tide $M_{j}$. For example, for tie rod T4, $F_{j 0}$ varies between $F_{10}=98 \mathrm{kN}$ (tide $M_{1}$ ) and $F_{20}=280.5 \mathrm{kN}\left(\right.$ tide $M_{2}$ ). During stage (2) the average value $F_{0}$ is computed and the identification is repeated 


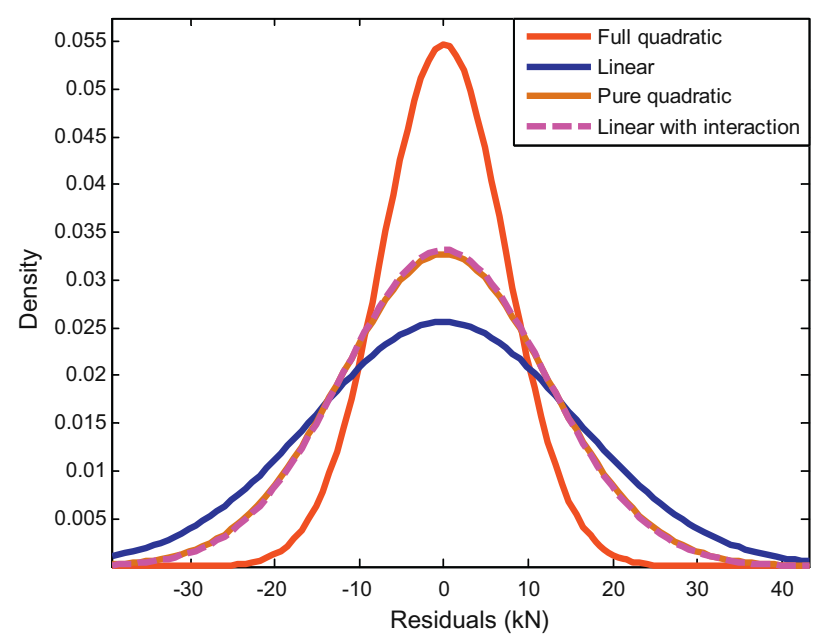

Fig. 8. Distribution of residuals for each response surface.

Table 9

Identification of $F_{0}$ for tie rods $\mathrm{T} 4$ and T21.

\begin{tabular}{lllll}
\hline T4 & & & T21 & \\
\cline { 5 - 5 } Tide & $F_{j 0}(\mathrm{kN})$ & & Tide & $F_{0}(\mathrm{kN})$ \\
\hline M1 & 98.0 & M1 & $3.37 \mathrm{e}-8$ \\
M2 & 280.5 & M2 & $2.12 \mathrm{e}-13$ \\
M3 & 143.0 & M3 & $2.42 \mathrm{e}-10$ \\
M4 & 198.0 & M4 & $4.42 \mathrm{e}-14$ \\
M5 & 115.0 & M5 & $4.61 \mathrm{e}-13$ \\
Average & 167.00 & Average & $\approx 0$ \\
\hline
\end{tabular}

for $X_{1}$ and $X_{2}$ to calculate the next iteration of $X_{j 1}^{(2)}$ and $X_{j 2}^{(2)}$. For example, for tie rod T4, $F_{0}=167 \mathrm{kN}$. Only the values computed during stage (2) are taken as solutions of the identification process. Table 9 shows the computed values of $F_{j 0}$ and the average $F_{0}$ for two tie rods, T4 and T21, selected as examples of the current section of the quay that does not have disturbing boundary effects. The mean values of pre-loading at these locations give an indication of the variability of the loads along the quay as measured during construction. Table 10, right, presents the results of the identification of $X_{j 1}$ and $X_{j 2}$ for tie rod T4 and 5 values of tides $M_{1}, \ldots, M_{5}$, with $F_{0}=167 \mathrm{kN}$. Table 10 , left, shows the evolution of the loading computed for $M_{1}$ from the identified values at each tide phase and the

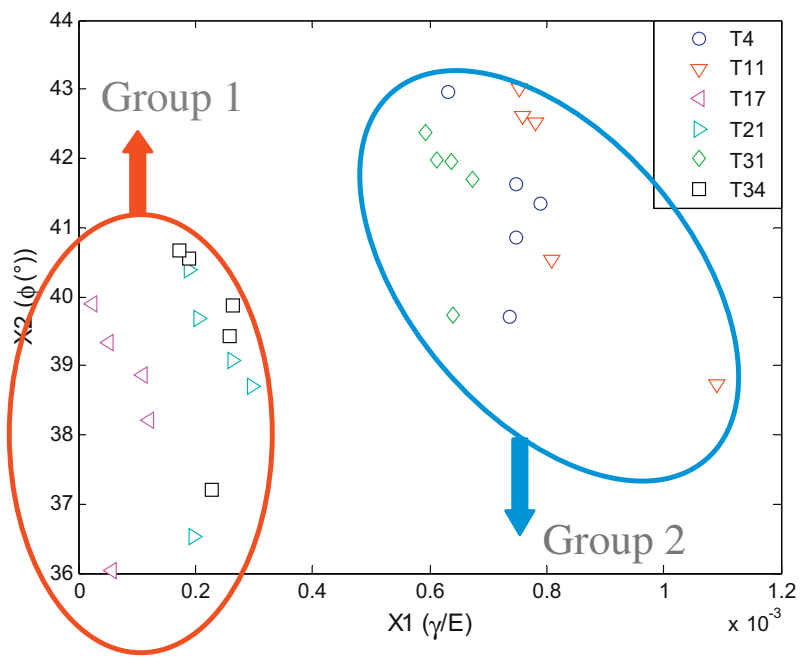

Fig. 10. Distributions of $X_{1}$ and $X_{2}$ for the two groups identified (CMAR =69).

measured loading. The comparison shows that the model fits the measured values extremely well. The results also show that the loading in tie rod T4 after identification is approximately $370 \mathrm{kN}$. The same procedure applied to the tie rod T21 results in a loading of approximately $120 \mathrm{kN}$. Results for the other tie rods are available in [35].

Results for $X_{1}$ and $X_{2}$ for all the tie rods and the 5 tides $M_{j}$ are shown in Fig. 10. Considering (Section 2.3) that only 6 tie rods are instrumented and that 5 tides with $\mathrm{CMAR}=69$ were recorded, a total of $30\left(X_{1}, X_{2}\right)$ couples are available for analysis. One result is that two different groups of tie rods emerge. The reason is still currently under discussion and should be found in the building methods. No specific algorithm has been used to sort them, and they appeared from two separate clouds of data. Therefore, in the following, two separate probability density functions (pdfs) have been fitted to the data.

The Pearson correlation coefficient between the two BRVs $X_{1}$ and $X_{2}$ for the two families of tie rods is calculated at 0.1252 and -0.423 for group 1 and group 2, respectively. Both of these correlation coefficients are low; thus the random variables can be assumed independent. Then, the probabilistic model can be selected based on polynomial chaos [15] or parametric distributions. There are not sufficient data available to implement the
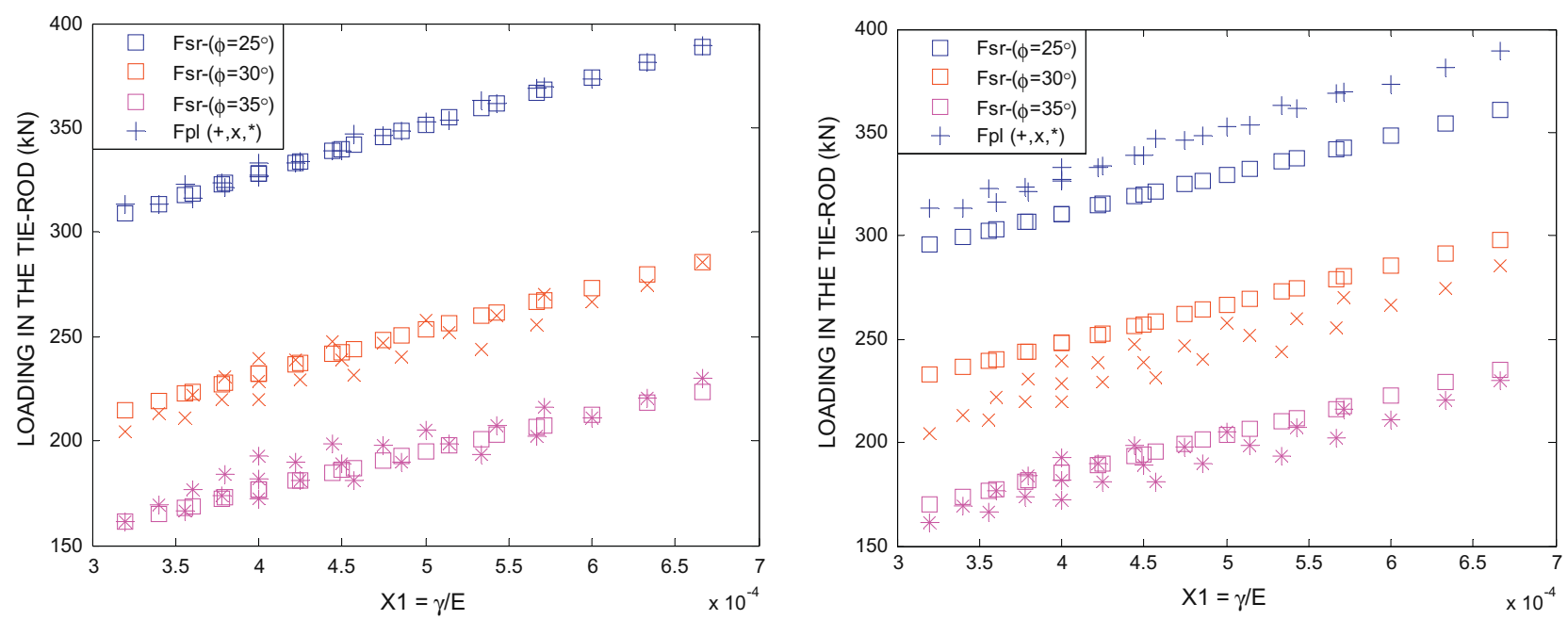

Fig. 9. Plaxis simulations (Fpl) and response surface (Fsr) for the full quadratic model (left) and the linear model (right). 
Table 10

Identification of variables $X_{1}$ and $X_{2}$ for tie rod T4.

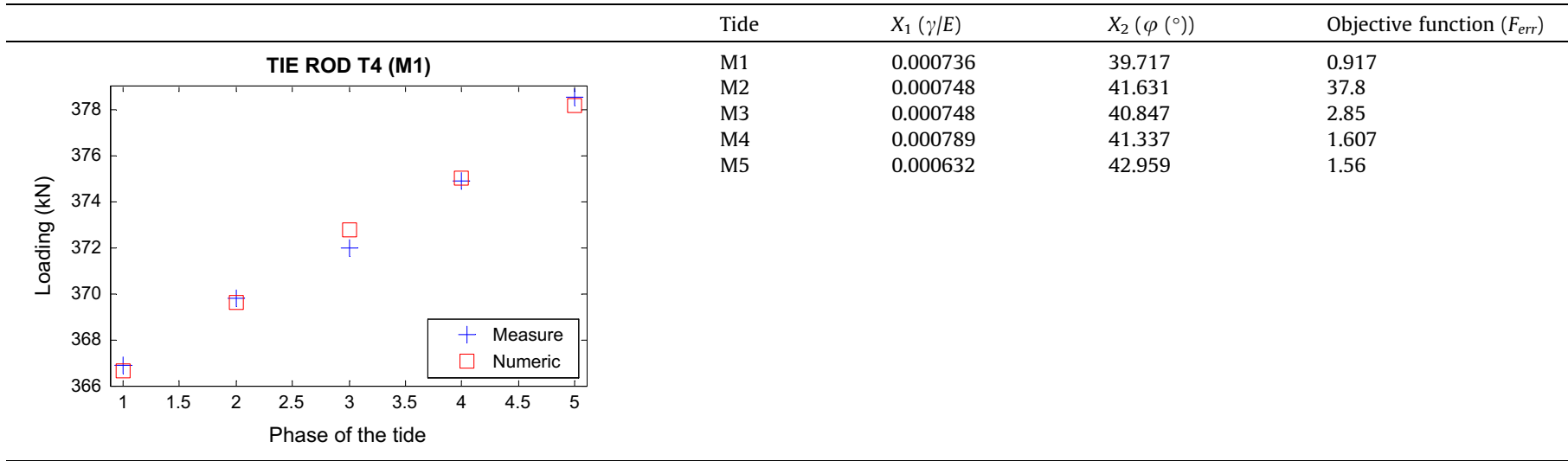

Table 11

Parameters of the $X_{1}$ and $X_{2}$ distributions.

\begin{tabular}{|c|c|c|c|c|c|c|c|c|}
\hline \multirow[t]{3}{*}{ Type and parameters of pdf } & \multicolumn{4}{|l|}{$X_{1}$} & \multicolumn{4}{|l|}{$X_{2}$} \\
\hline & \multicolumn{2}{|l|}{ Group 1} & \multicolumn{2}{|l|}{ Group 2} & \multicolumn{2}{|l|}{ Group 1} & \multicolumn{2}{|l|}{ Group 2} \\
\hline & Normal & Log-normal & Normal & Log-normal & Normal & Log-normal & Normal & Log-normal \\
\hline$\mu$ & $1.75 e-4$ & -8.84 & $7.72 \mathrm{e}-4$ & -7.18 & 38.97 & 3.66 & 41.67 & 3.73 \\
\hline$\sigma$ & $8.6 e-5$ & 0.738 & $1.43 e-4$ & 0.1774 & 1.42 & 0.037 & 1.23 & 0.03 \\
\hline Likelihood & 119.67 & 116.308 & 112.02 & 113.11 & -26.04 & -26.26 & -23.89 & -24.02 \\
\hline
\end{tabular}
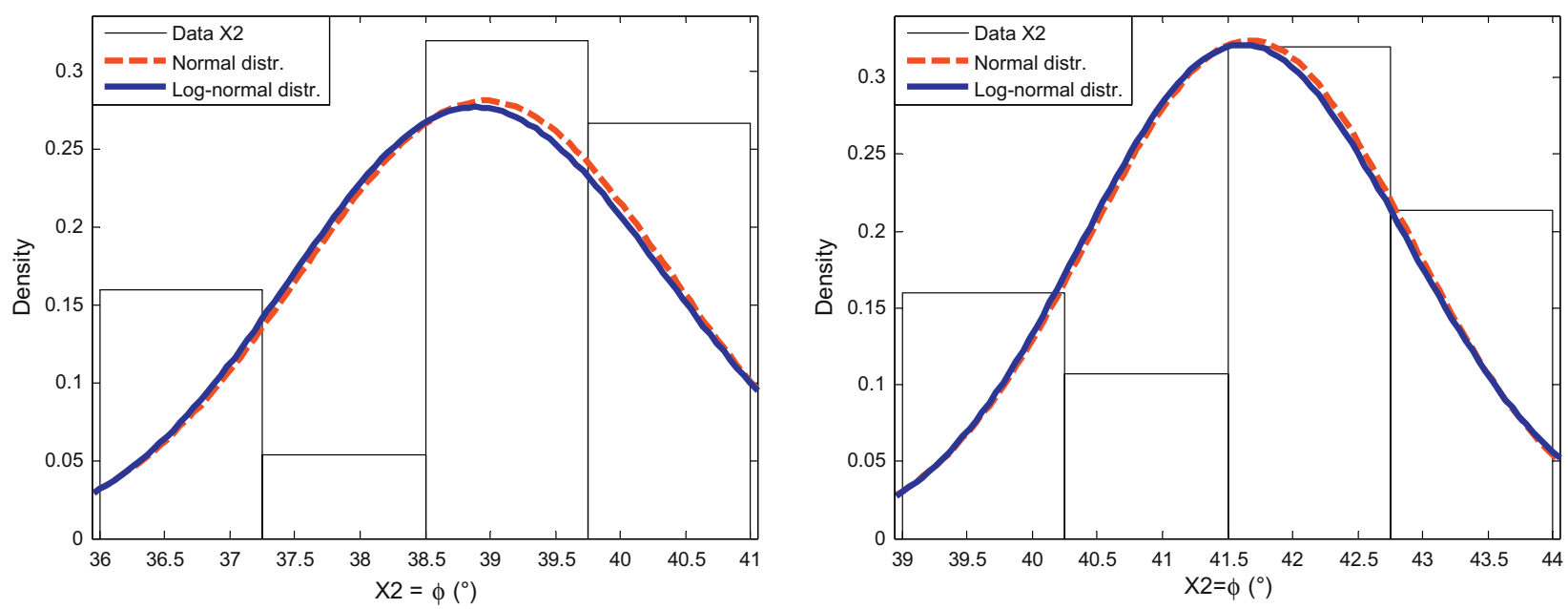

Fig. 11. Distribution of $X_{2}$, group 1 (left) and group 2 (right).

polynomial chaos approach; therefore, the parametric distributions approach is used in this study. To retrieve the best distribution fit for each group of tie rods, a combination of three parameters is used. The parameters are the mean, $\mu$, the standard deviation, $\sigma$, and the maximum likelihood estimation. Table 11 presents the values of these parameters for the two BRVs using the assumptions of normal and log-normal probability density functions. The results are plotted in Fig. 11 for the variable $X_{2}$. The distribution can be well-fitted by both normal and log-normal pdfs. The distributions contain acceptable values in comparison to the literature, with reasonable scatter (Table 11).

\subsection{Verification and validation}

Using the fitted distributions above, a direct Monte Carlo simulation is used to verify and validate the results. The simu- lation is used to compute the bounds of a confidence interval. In this study, a 90\% confidence interval with percentiles 5\% and $95 \%$ is selected. That is, $10 \%$ of the measurements are accepted to be outside the interval. Other tide levels (CMAR $=89$ and 100) at different dates are used to validate the accuracy of the response surface model. Fig. 12 presents the loading evolution in tie rod T4 during the 2-year period (2004-2005). This period includes three tides with CMAR $=69$ used for the identification. The tides with $\mathrm{CMAR}=89$ and 100 are selected for verification.

To demonstrate the validity of the proposed model, it must be tested for a generic tide, independent of its CMAR. Fig. 12 shows that the loading in tie rod T4 undergoes a significant change with time between approximately $275-370 \mathrm{kN}$; this has been noted by [8] and is because of external factors and a global stabilisation of the wharf. Using a simple moving average of the three tides sam- 

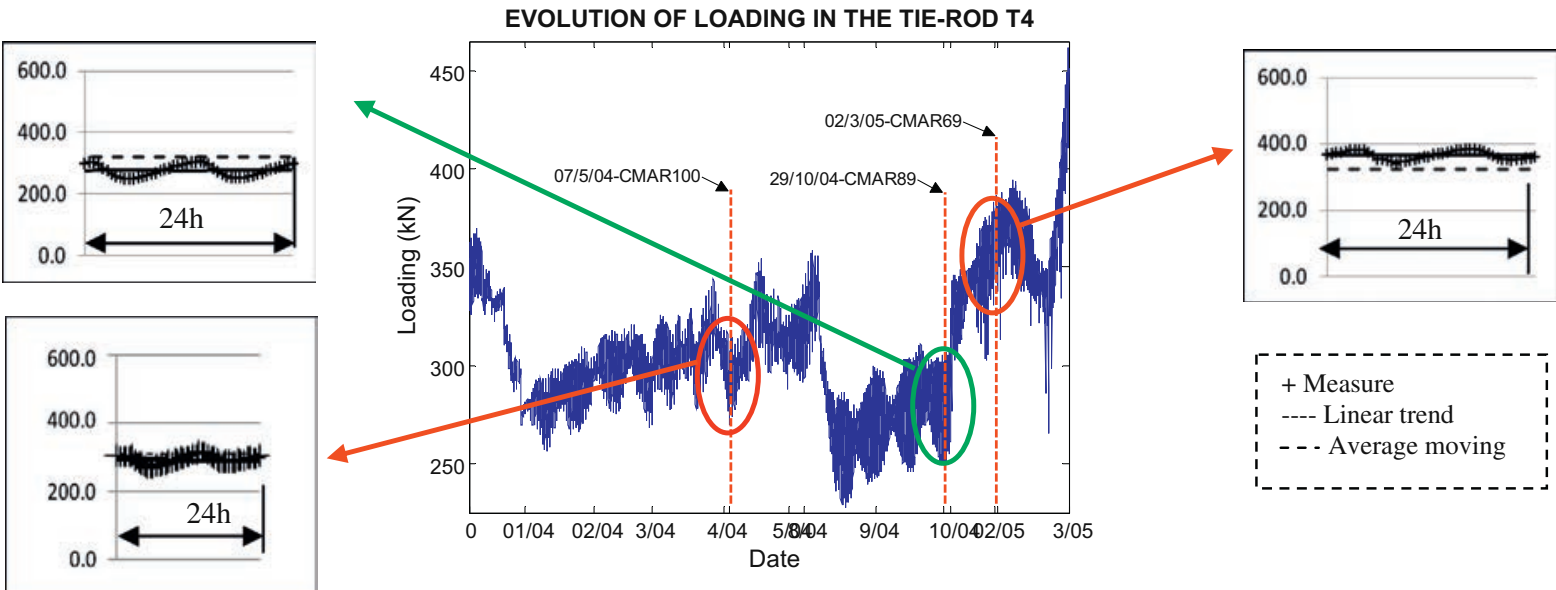

Fig. 12. Evolution of loading in tie rod $T 4$.
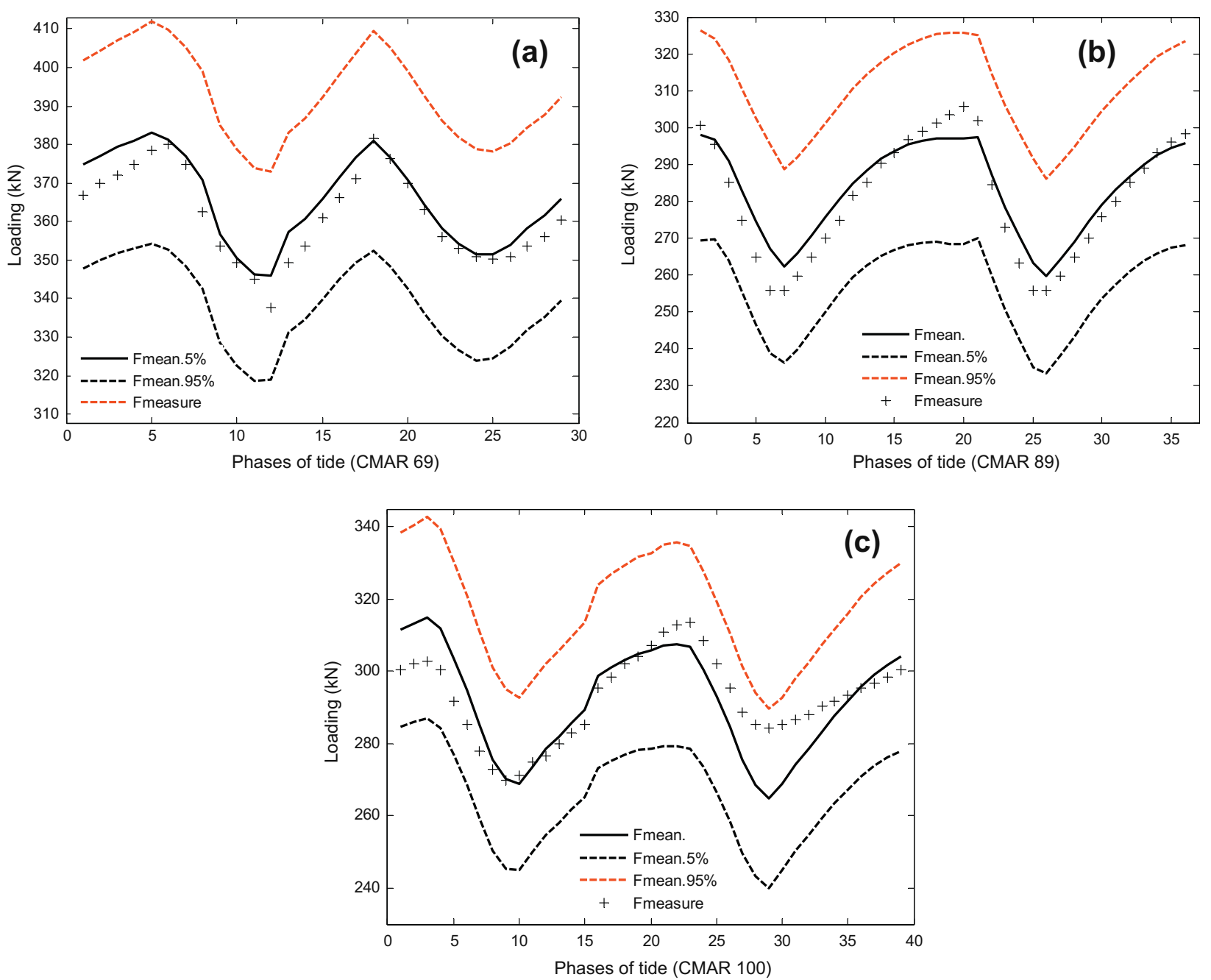

Fig. 13. Evolution of measured and modelled loading with time for $T 4$ for a tide with: (a) $C M A R=69$, (b) $C M A R=89$ and (c) $C M A R=100$.

pled (corresponding to CMAR $=100$ and 89 for the first and second periods, and CMAR $=69$ for the last period), a substantial loading stability is calculated (Fig. 12). To validate the results obtained for the tide with CMAR =69 (registered on 2/3/2005) for other tides (e.g., with CMAR $=89$, registered on $29 / 10 / 2004$, and with
CMAR $=100$, registered on $07 / 5 / 2004$ ), the values of the moving average in Eq. (7) are used to simulate the loading in tie rod T4 at $\mathrm{CMAR}=89$ and 100 as follows:

$F_{T}(t)=F_{\mathrm{Sr}}(t)-\Delta F_{\mathrm{MM}}$ 
where $F_{T}(t)$ is the loading in the tie rod at generic time $t, F_{\mathrm{sr}}(t)$ is the loading in the tie rod calculated by QRS and $\Delta F_{M M}$ is the loading deviation between the moving average values at the instant $t$ and $t_{r e f}$, where $t_{\text {ref }}$ corresponds to the same instant but during the reference tide (where CMAR $=69$ ).

A simple moving average can be calculated using Eq. (8) as follows:

$\bar{x}_{n}=\frac{1}{N} \sum_{k=0}^{N-1} x_{k-N} \quad$ or $\quad \bar{x}_{n}=\bar{x}_{n-1}+\frac{x_{n}-x_{n-N}}{N}$

where $N$ denotes the number of values selected for the moving average. $N=48$ has been shown to fit the medium trend (season) and corresponds to the number of measurements during a day. The value of the loading deviation, $F_{\mathrm{MM}}$, in Eq. (9), can be written as follows:

$F_{\mathrm{MM}}=F_{\mathrm{MMC}}+F_{\mathrm{Ln}}$

where $F_{\mathrm{MMC}}$ denotes the central moving average of the loading around the linear trend loading, $F_{\mathrm{Ln}}$.

Fig. 13a shows the load in tie rod T4 $($ CMAR $=69)$ and it shows that the model fits the measured loads well, i.e., the measurements are close to the measured mean value and remain in the 5-95\% fractile of the output distribution of the model. Fig. 13b and c shows the loading in tie rod T4 for tides with $\mathrm{CMAR}=89$ and 100. In these cases, the plots show a good agreement between measurements and the proposed model; i.e., the measurements remain in the 5-95\% fractile of the output distribution of the model.

\section{Conclusions}

The monitoring of infrastructures is currently used for damage detection. This study focuses on another challenge, namely, the identification of a model's characteristics from measured data. The method is applied to the geotechnical parameters of an embankment of a wharf. Because of the intrinsic uncertainties in the model and hazardous physical parameters, probabilistic modelling is used. A surrogate is initially provided to the original model, with a numerical database. This study uses a quadratic response surface. The full quadratic response surface is shown to be the most efficient approximation to fit the finite element model. A reduction in the number of random variables of the numerical model is suggested and the response surface is used to identify distributions of parameters. Two groups of tie rods are then identified and the corresponding empirical distributions are provided. It is shown that both normal and log-normal probability distribution functions fit the frictional angle values. Verification and validation of the response surface model show that both the QRS and the distribution of identified parameters can be used to model the inherent uncertainties.

\section{References}

[1] Boéro J, Schoefs F, Capra B, Rouxel N. Risk management of French harbour structures: Part 1. Description of built assets. PARALIA 2009;2:6.1-6.11.

[2] Boéro J, Schoefs F, Capra B, Rouxel N. Risk management of French harbour structures: Part 2. Current practices, needs - experience feedback of owners. PARALIA 2009;2:6.13-24.

[3] Del Grosso A. Monitoring of infrastructures in the marine environment. In: Casciati F, Magonette G, editors. Proc 3rd int workshop on structural control for civil and infrastructure engineering, Paris; 2000.

[4] Martin NJ, Bell SI. The restoration of Shuaiba oil pier, Kuwait. In: Proc int conf on monitoring and control of marine and harbour structures, Genoa; 1999.

[5] Vallone M, Giammarinaro S. Monitoring of Termini Imerese harbour (Sicily, Italy) using satellite DInSAR data. In: Proc IV int conf applied geophysics for engineering, Messina; 2007.

[6] Donahue MJ, Dickenson SE, Miller TH, Yim SC. Implications of the observed seismic performance of a pile supported wharf for numerical modeling. Earthquake Spectra 2005;21(3):617-34
[7] Sundaravadivelu R, Gopala Krishna M, Chellappan V. Monitoring the behaviour of diaphragm walls of a dry dock. In: Proc int conf on monitoring and control of marine and harbour structures, Genoa; 1999.

[8] Yáñez-Godoy H, Schoefs F, Casari P. Statistical analysis of the effects of building conditions on the initial loadings of on-piles quays. J Struct Health Monit 2008;7(3):245-63.

[9] Lanata F, Schoefs F. Multi-algorithm approach for identification of structural behaviour of complex structures under cyclic environmental loading. J Struct Health Monit 2012;11(1):51-67.

[10] Yáñez-Godoy H, Schoefs F, Nouy A, Casari P. Extreme storm loading on inservice wharf structures: interest of monitoring for reliability updating. Revue Européenne de Génie Civil 2006;5(10):565-81.

[11] PLAXIS. Reference manual, version 8; 2003.

[12] Rechea C, Levasseur S, Finno R. Inverse analysis techniques for parameter identification in simulation of excavation support systems. Comput Geotech 2008;35:331-45.

[13] Schoefs F. Sensitivity approach for modeling the environmental loading of marine structures through a matrix response surface. Reliab Eng Syst Saf 2008;93(7):1004-17.

[14] Boéro J, Schoefs F, Yáñez-Godoy H, Capra B. Time-function reliability of harbour infrastructures from stochastic modelling of corrosion. Eur J Environ Civil Eng 2012;16(10):1187-201.

[15] Schoefs F, Yáñez-Godoy H, Lanata F. Polynomial chaos representation for identification of mechanical characteristics of instrumented structures: application to a pile supported wharf. Comput Aided Civil Infrastruct Eng 2011;26(3):173-89.

[16] Baroth J, Breysse D, Schoefs F. Construction reliability. Wiley: ISTE Ltd.; 2011.

[17] Borges JL. Three dimensional analysis of embankment on soft soils incorborating vertical drains by finite element method. Comput Geotech 2004;31(8):665-76

[18] Leira BJ, Holmås T, Ferfjord K. Response surface parametrization for estimation of fatigue damage and extreme response of marine structures. In: Proc int 9th conf on application of statistics and probability in civil engineering, Millpress, Rotterdam; 2003. p. 589-98 [1(1)].

[19] Bouyssy V, Rackwitz R. Approximation of non-normal responses for drag dominated offshore structures. In: Proc int 6th conf on reliability and optimization of structural systems, Chapman and Hall; 1994. p. 161-8.

[20] Faravelli L. Response surface approach for reliability analysis. J Eng Mech (ASCE) 1989;115(12):2763-81

[21] Faravelli L. Structural reliability via response surface. In: Proc on Iutam symposium on nonlinear stochastic mechanics, Springer-Verlag; 1992. p. 213-23.

[22] Muzeau JP, Lemaire M, Besse P et Locci JM. Evaluation of reliability in case of complex mechanical behavior. In: Proc on safety and reliability, vol. 2; 1993. p. 47-56.

[23] Labeyrie J. Response surface methodology in structural reliability. Probabilistic methods for structural design. Solid mechanics and its applications, vol 56. Kluwer Academic Publishers; 1997. p. 39-58.

[24] Boero J. Fiabilité des infrastructures portuaires: approche innovante d'analyse et de modélisation probabiliste des données d'inspection. PhD thesis. Thèse sciences l'ingénieur Génie Civil et mécanique, Université de Nantes-UFR Sciences et techniques, Ecole doctorale «Sciences pour ingénieur, Géosciences, Architecture»; 2010.

[25] Martel S. Etude expérimental et méthologique sur le comportement des écrans de soutènement. PhD thesis. Thèse géotechnique de docteur de l'école nationale des ponts et chaussées; 2005.

[26] Tanchaisawat T, Bergado DT. Numerical simulation and sensitivity analyses of full-scale test embankment with reinforced lightweight geomaterials on sof Bangkok clay. Geotext Geomembr 2008;26(6):498-511.

[27] Bergado DT, Youwai S, Teerawattanasuk C, Visudmedanukul S. The interaction mechanism and behavior hexagonal wire mesh reinforced embankment with silty sand backfill on soft clay. Comput Geotech 2003;30(6):517-34.

[28] Chang KT, Sture S. Microplane modelling of sand behavior under nonproportional loading. Comput Geotech 1997;21(3):183-216.

[29] Takahaskhi A, Takemura J. Liquefaction-induced large displacement of pilesupported wharf. Soil Dyn Earthquake Eng 2005;25(11):811-25.

[30] Hinchberger SD, Rowe KR. Geosynthetic reinforced embankment on soft clay foundations: predicting reinforcement trains at failure. Geotext Geomembr 2003;21(3):151-75.

[31] Borges JL, Cardoso AS. Structural behavior and parametric study of reinforced embankment on soft clays. Comput Geotech 2001;28(3):209-93.

[32] Huang Jie, Han Jie. Two-dimensional parametric study of geosynthetic reinforced column-supported embankment by coupled hydraulic and mechanical modeling. Comput Geotech 2010;37(5):638-48.

[33] Sharma JS, Bolton MD. Centrifugal and numerical modelling of reinforced embankment on soft clay installer with wick drain. Geotext Geomembr $2001 ; 19(1): 164-74$.

[34] Tandjiria V, Low BK. Effect of reinforcement force distribution on stability of embankment. Geotext Geomembr 2002;20(6):423-43.

[35] Le KT. Identification des caractéristiques aléatoires de remblais à partir du suivi de santé des structures: application aux structures portuaires. PhD thesis. Thèse sciences l'ingénieur Génie Civil et mécanique, Université de Nantes-UFR Sciences et techniques, Ecole doctorale «Sciences pour ingénieur, Géosciences, Architecture»; 2012.

[36] Lagarias JC, Reeds JA, Wright MH, Wright PE. Convergence properties of the Nelder-Mead simplex method in low dimensions. SIAM J Optimiz 1998;1:112-47. 